\title{
Solanum nigrum Unripe fruit fraction attenuates Adriamycin resistance by down- regulating multi-drug resistance protein (Mdr)-1 through Jak-STAT pathway
}

Sankar Jagadeeshan ${ }^{1,3+}$, Diana David ${ }^{1 \dagger}$, S. Jisha ${ }^{2 \dagger}$, S. Manjula ${ }^{2}$ and S. Asha Nair ${ }^{1 *}$

\begin{abstract}
Background: Solanum nigrum, herbal plant that commonly grows in temperate climate zone, has been used as a traditional folk medicine whose ripen fruits were proven to exhibit anti-tumor properties. In traditional Chinese medicine, it has been used for centuries to cure inflammation, edema, mastitis and hepatic cancer and in the Ayurvedic system of traditional medicine in India, S. nigrum is applied against enteric diseases, ulcer, diarrhea and skin diseases. A methanolic glycosidic extract fraction of unripe fruit of S. nigrum (SNME) was investigated for its anticancer property and possible mechanism to surmount adriamycin resistance in NCI/ADR-RES cells.
\end{abstract}

Methods: The NCI/ADR-RES cells were treated with 7.8125, 15.625, 31.25, 62.5, 125 and $250 \mu \mathrm{g} / \mathrm{ml}$ of methanolic extract of S. nigrum (SNME) for 12, 24 and 48 h, to check the cell viability and proliferation. The cells were also exposed to adriamycin alone or in combination with SNME and the effects on cell growth were determined by MTT. Cell cycle analysis, Ethidium bromide and Acridine orange staining, Annexin-binding efficiency, nuclear condensation and DNA fragmentation of the apoptotic NCI/ADR-RES cells were also determined. To elucidate the relationship between SNME and multi drug resistance, we analyzed the expression levels of Mdr-1, JAK1, STAT3, and PSTAT3 in NCI/ADR-RES cells after treatment with SNME.

Results: Results from the cytotoxicity assay showed a direct correlation between the concentration of methanolic glycosidic extract fraction of S. nigrum (SNME) and the surviving cell population. Combination with Adriamycin, SNME exhibits a synergistic action on NCl/ADR-RES cells, giving the first line of evidence to overcoming Adriamycin resistance. The SNME mediated cell growth suppression was proven to be apoptotic, based on results obtained from DNA fragmentation, annexin $V$ apoptosis assaay and PARP cleavage analysis. Looking into the molecular insight SNME surpasses the chemoresistance of NCI/ADR-RES cells by inhibiting the JAK-STAT3 signaling pathway through the down regulation of JAK1, STAT3, PSTAT3, and Mdr1 expression.

Conclusions: Collectively our findings suggest that unripe fruit of Solanum nigrum could possibly be used as a chemosensitizing agent against Adriamycin resistant cancers.

Keywords: Solanum nigrum, Unripe fruits, Methanolic extract, Glycosidic fraction, Cancer, Adriamycin resistance

\footnotetext{
* Correspondence: sasha@rgcb.res.in

${ }^{\dagger}$ Equal contributors

${ }^{1}$ Cancer Research Program, Rajiv Gandhi Centre for Biotechnology,

Thiruvananthapuram, Kerala, India

Full list of author information is available at the end of the article
} 


\section{Background}

According to World Health Organization (WHO), death due to cancer is expected to increase 104\% worldwide by the year 2020 with the largest increase $(70 \%)$ predicted to occur in developing countries [1]. Chemotherapy is one of the most frequently used therapeutic modalities for cancer treatment. The development of resistance to chemotherapy poses a significant problem to patients who rely on conventional cytotoxic agents for the treatment of malignant disease. In recent years, there has been a global trend toward the isolation and identification of bioactive phytochemicals present in fruits, vegetables and herbs which possess substantial anti-carcinogenic properties [2]. Most of these bioactive substances exert their cancer chemotherapeutic activity by blocking cell cycle progression and triggering apoptotic cell death. Therefore, induction of apoptosis in tumor cells has become an indicator of the tumor treatment response in employing a plant derived bioactive substance to reduce and control human mortality due to cancer [3]. Recently, several studies have documented the ability of chemo-preventive phytochemicals to increase the sensitivity of cancer cells to anticancer drugs [4].

Solanum nigrum, an herbal plant that commonly grows in temperate climate zone, has been used as a traditional folk medicine because of its antiperiodic, antiphlogistic, diaphoretic, diuretic, emollient, febrifuge, narcotic, purgative and sedative effects. In traditional Chinese medicine, it has been used for centuries to cure inflammation, edema, mastitis and hepatic cancer [5]. In the ayurvedic system of traditional medicine in India, $S$. nigrum is applied against enteric diseases, ulcer, diarrhea and skin diseases.

Phytochemical investigations on S. nigrum whole plant reported that it contains alkaloids, flavonoids, tannins, saponins, glycosides, proteins, carbohydrates, coumarins and phytosterols and these bioactive principles shown to exhibit antitumor activity [6-9]. Son et al. [10], reported that ethanolic extract of $S$. nigrum has antiproliferative, apoptotic and cytotoxic effects on MCF- 7 cells. There are several reports which emphasize the role of extracts from S. nigrum berries as an antioxidant, antitumor, hepatoprotective, anti inflammatory and anti convulsant action [5, 11-15]. Even though vast literature study and experimental result analysis showed that $S$. nigrum employs various immunological applications in cancer, the beneficial role of its unripe berry extract on drug resistance in cancer has not yet been studied in detail.

Multi-drug resistance (Mdr1) gene, also known as ABCB1 gene, encodes an efflux transporter Pglycoprotein (P-gp) that limits a wide variety of drugs from penetrating cells and depositing them into the extracellular space [16, 17]. Since the MDR1 gene and $\mathrm{P}$-gp were proved to induce drug resistance in certain tumors, pharmacogenetics concepts has had a significant impact on individual response of drug treatment and genotyping has been considered a new tool for predicting individual drug-metabolizing capabilities and therapeutic establishment [18]. Compelling evidence has now established that aberrant STAT3 expression has a critical role in the development, progression and drug resistance of human tumors. STAT3's functions and its critical roles in tumorigenesis and tumor maintenance have qualified it as a valid target for the development of novel anticancer therapeutic modalities [19-21]. Several studies indicated a significant association between STAT3 expression and drug resistance in cancer. Inhibition of STAT3 activity enhanced chemosensitivity in hepatocellular carcinoma, stomach carcinoma and melanoma [22-24]. Additionally, some researchers demonstrated that multidrug resistance was consistent with STAT3 mRNA overexpression in cisplatin-resistant lung cancer cells [25] and STAT3 activity was found to be specifically elevated in drug-resistant neuroblastoma and ovarian cancer cells, while not in relevant drug sensitive cells [26]. Recently, it was demonstrated that inhibition of STAT3 effectively enhanced multidrug sensitivity via inhibiting Nanog/STAT3-mediated mdr1 gene expression in both MCF-7 cells and SK-OV-3.ipl cells [27]. Clinically, STAT3 is highly activated in drug non-sensitive advanced tumors. All these findings suggested that STAT3 might be associated with multi-drug resistance in various tumors and their relation need to be further explored.

Earlier studies done in our lab using methanolic extract of S. nigrum exhibited estrogen receptor (ER) dependent growth inhibition in MCF-7 cells and in vivo studies showed a classical uterotrophic response in ovariectomized mice elicited by S. nigrum [28]. Hence, this study was conducted to evaluate the chemosensitization efficacy of SNME on adriamycin resistant cancer cells (NCI/ADR-RES) and tried at deciphering the possible involvement of SNME on STAT3 mediated chemotherapy resistance in adriamycin resistant cancer cells (NCI/ADR-RES).

\section{Methods \\ Plant materia}

Authentic certified seeds of $S$. nigrum (Acc No. IC 298650) procured from National Bureau of Plant Genetic Resources (NBPGR), Kerala Agricultural University Campus, Thrissur, Kerala, were planted and maintained in the green house of Rajiv Gandhi Centre for Biotechnology, Trivandrum, Kerala under uniform conditions of temperature and humidity. 


\section{Phytochemical extraction}

Mature, unripe fruits from 2 months old plants were collected, washed and oven dried at $60{ }^{\circ} \mathrm{C}$. Uniformly dried fruits were powdered and $100 \mathrm{~g}$ of dried powder was used for soxhlet analysis. Extraction was carried out sequentially with $250 \mathrm{ml}$ hexane and $250 \mathrm{ml}$ chloroform at $50{ }^{\circ} \mathrm{C}$ for $18 \mathrm{~h}$ to remove the less polar lipid components and finally with $250 \mathrm{ml}$ methanol at a temperature of $50{ }^{\circ} \mathrm{C}$ for $18 \mathrm{~h}$ to obtain the glycoside fraction. The defatted methanol fraction was further purified in silica gel glass column (Borosil) using the solvent mixture of 66 methanol: 33 chloroform: 1 glacial acetic acid as the mobile phase. The fractions were separately analyzed for the presence of glycosides by Thin Layer Chromatography (TLC) performed on pre-coated TLC plates (Silica gel 60 TLC Plates, Merck).

\section{HPLC analysis}

The methanolic fraction was evaporated to dryness under vacuum using rota-evaporator (Buchi Lab Equipments, USA) and stored at $4{ }^{\circ} \mathrm{C}$ for HPLC analysis. For preparation of standard, $10 \mathrm{mg}$ of $\alpha$-solanine (Sigma, USA) was weighed and added to a $10 \mathrm{~mL}$ volumetric flask, and made up to $10 \mathrm{~mL}$ with methanol (HPLC grade, Merck). $100 \mathrm{mg}$ of the extract was weighed and made up to $100 \mathrm{~mL}$, followed by filtration through a Millex syringe-driven filter unit (Millipore Corporation, Bedford, USA) before injection. The sample injection volume was $2.0 \mu \mathrm{l}$ and the chromatogram was recorded at $210 \mathrm{~nm}$. HPLC was performed in model LC-10AT vp (Shimadzu Corporation, Kyoto, Japan) using C18 column ( $3 \mu \mathrm{m}$ size, $5 \mathrm{~cm} \times 2.1 \mathrm{~mm}$ in length; Supelco, USA) with water-acetonitrile (HPLC grade; Merck, Darmstadt, Germany) as the mobile phase. Separation was carried out at a flow rate of $0.2 \mathrm{~mL} / \mathrm{min}$.

\section{Cell culture}

NCI/ADR-RES cell line was obtained from National Cancer Institute (NCI, USA). The cells were maintained in DMEM (Sigma, USA) containing 10\% heat inactivated FBS (GIBCO, USA) and 1\% antibiotic-antimycotic cocktail (GIBCO, USA).

\section{Cell viability assay}

Briefly, cells (5000 cells/well) were seeded into a 96 well plate and incubated for $24 \mathrm{~h}$. After $24 \mathrm{~h}$, cells were replenished with fresh medium containing different concentration of compound. After $48 \mathrm{~h}$ of incubation, MTT (500 $\mu \mathrm{g} / \mathrm{ml}$ final concentration, Sigma, USA) was added to each well and incubated for $4 \mathrm{~h}$ in order to allow the conversion of MTT to formazan crystals. Finally, the formazan crystals formed were dissolved in isopropyl alcohol and the OD was measured at $570 \mathrm{~nm}$ using ELISA microplate reader (Bio Rad, USA). The amount of formazan crystals formed is directly proportional to the viability of cells and the percentage growth inhibition by the compound was calculated and tabulated.

\section{Combination treatment}

NCI/ADR RES cells were exposed to adriamycin alone or in combination with SNME, for $48 \mathrm{~h}$, and the effects on cell growth were determined by MTT. Synergistic efficacy was determined by the isobologram and combination-index methods of Chou and Talalay (CompuSyn Software [29, 30],).

\section{Cell cycle analysis}

Cell cycle progression was identified by measuring the DNA content. Briefly, cells after treatment, were trypsinized, washed twice in PBS and fixed using $70 \%$ of ice cold ethanol for $30 \mathrm{~min}$. Fixed cells were washed twice and treated with $200 \mu \mathrm{g} / \mathrm{ml}$ of RNase A at $37^{\circ} \mathrm{C}$ for $1 \mathrm{~h}$. Finally propidium iodide was used to stain the cells. Analysis was done in FACS Aria (BD, Mountain View, CA, USA) using BD FACS Diva software.

\section{Apoptotic assays}

$2 \times 10^{5}$ cells were seeded in a $35 \mathrm{~mm}$ culture dish and SNME treatment was given at $125 \mu \mathrm{g} / \mathrm{ml}$ for $24 \mathrm{H}$. medium was removed and the cells were washed with phosphate buffered saline. The cells were then given a combined staining of acridine orange $(50 \mathrm{mg} / \mathrm{ml})$ and ethidium bromide $(5 \mathrm{mg} / \mathrm{ml})$ for $5 \mathrm{~min}$ at room temperature, and examined by an inverted fluorescence microscope. Similar method was followed for Hoechst staining $(5 \mathrm{mg} / \mathrm{ml})$ except for the final step in which the cells were given an incubation period of $15 \mathrm{~min}$ at $37^{\circ} \mathrm{C}$ before visualization.

For annexin-binding assay, $1 \times 10^{6}$ cells were seeded in $60 \mathrm{~mm}$ culture dishes. SNME treatment was given $(125 \mu \mathrm{g} / \mathrm{ml}$ for $12 \mathrm{~h}$ and $24 \mathrm{~h})$ and the cells were harvested and stained with FITC-labeled annexin using Annexin V-FITC Apoptosis Detection Kit according to the manufacturer's instruction, and a flow cytometric analysis was carried out using FACS Aria (Special order system, BD, USA).

\section{DNA fragmentation assay}

$1 \times 10^{6}$ cells were harvested after SNME treatment for $24 \mathrm{~h}$, washed, and incubated in $20 \mu \mathrm{l}$ of $50 \mathrm{mM}$ Tris$\mathrm{HCl}$ (pH 8.0), $10 \mathrm{mM}$ EDTA, 0.5\% SDS, and $0.5 \mu \mathrm{g} / \mathrm{ml}$ proteinase K (Sigma) for $1 \mathrm{~h}$ at $50{ }^{\circ} \mathrm{C} .10 \mu \mathrm{l}$ of $0.5 \mu \mathrm{g} / \mathrm{ml}$ RNase A was added and incubated for $1 \mathrm{~h}$. The digested samples were incubated with $10 \mu \mathrm{l}$ of $10 \mathrm{mM}$ EDTA $(\mathrm{pH} 8.0), 0.25 \%$ bromophenol blue, and $40 \%$ sucrose at $70{ }^{\circ} \mathrm{C}$. The DNA was separated in $2 \%$ agarose gel and visualized by ultraviolet (UV) illumination after ethidium bromide staining. 


\section{Immunoblot analysis}

$2 \times 10^{6}$ cells were seeded in $100-\mathrm{mm}$ culture dishes and SNME was given at different concentrations $(7.8,15.6$, $31.2,62.5$, and $125 \mu \mathrm{g} / \mathrm{ml})$ and time periods $(6,12,24$ and $48 \mathrm{~h}$ ). Cells were then lysed using lysis buffer comprising 10\% NP40, $5 \mathrm{M} \mathrm{NaCl}, 1 \mathrm{M}$ HEPES, 0.1 M DTT, 0.1 M EGTA, 0.1 M EDTA, protease inhibitors (Sigma, USA) and total cell extract was obtained by differential centrifugation $(14,000 \mathrm{rpm}$ for $10 \mathrm{~min})$. The protein concentrations were determined using Bradford's assay and $60 \mu \mathrm{g}$ of proteins were resolved by $10 \%$ SDS-PAGE, and the separated proteins were electrotransferred onto nitrocellulose membrane (Amersham Pharmacia Biotech, USA). After pre-blocking these membranes with $5 \%$ skimmed milk, they were treated with antibodies against STAT3 (1:200, Santa Cruz Biotechnology, USA), pSTAT3 (Tyr 705) (1:200, Santa Cruz Biotechnology, USA), pSTAT3 (Ser 727) (1:100, Cell Signaling, USA), JAK1 (1:300, Cell Signaling, USA), PARP (1:100, Cell Signaling, USA), Mdr1 (1:100, Santa Cruz Biotechnology, USA), and $\beta$ - actin (1:5000, Sigma, USA) as primary antibodies and incubated overnight at $4{ }^{\circ} \mathrm{C}$. Horseradish peroxidase-conjugated anti-rabbit (1:5000, Santa Cruz Biotechnology, USA) and anti-mouse (1:5000, Santa Cruz Biotechnology, USA) antibodies were used as secondary antibodies and incubated for $1 \mathrm{~h}$ at room temperature. Immunoreactive bands were developed with an ECL system (Amersham Pharmacia Biotech, Uppsala, Sweden).

\section{Result}

\section{HPLC analysis}

The retention time for $\alpha$-solanine was around $30 \mathrm{~min}$ (Fig. 1a). A comparable peak was observed for the extract, which indicates the presence of $\alpha$-solanine in the glycoside fraction (Fig. 1b). The presence of $\alpha$-solanine which is the main glycoside, was also confirmed by TLC.
The additional peaks indicate the presence of more glycosides. FAB/MS (Jeol SX-102, Japan) was performed with the glycoside fractions, which indicated the presence of two major peaks representing glycosides with molecular weights 884.06 and 884 , which coincides with those of known glycosides like solasonine and solamargine respectively. Altogether, our results suggest the presence of at least three known Solanum glycosides viz. $\alpha$-solanine, solasonine and solamargine in the extract. However, detailed analysis could not be performed due to lack of availability of these solasonine and solamargine standards.

\section{SNME inhibits cell proliferation}

We first examined the inhibitory action of SNME on NCI/ADR-RES cells by MTT assay. NCI/ADR-RES cells were treated with serial concentrations of SNME for different time intervals as shown in Fig. 2a. SNME inhibited cell proliferation in a dose and time dependent manner. We could attain a $50 \%$ inhibition at about $125 \mu \mathrm{g} / \mathrm{ml}$ of the SNME for about $24 \mathrm{~h}$. On prolonged incubation of SNME for $48 \mathrm{~h}$, the percentage inhibition rose with increase in concentration. Similar pattern of result was obtained on cell viability analysis using trypan blue assay (Fig. 2b).

\section{SNME synergistically act with Adriamycin on combination treatment}

To determine whether the SNME sensitizes Adriamycin resistant NCI/ADR RES cells to Adriamycin, the cells were treated with varying concentration of Adriamycin in combination with varying concentration of SNME (Fig. 2c). Synergy was evaluated using the CompuSyn Software and observed at multiple drug concentrations resulting in combination indices under 0.5 at $F a$ of 0.5 (50\% reduction of cell growth) (Fig. 2d). Combination treatment of SNME with Adriamycin indicate a synergistic
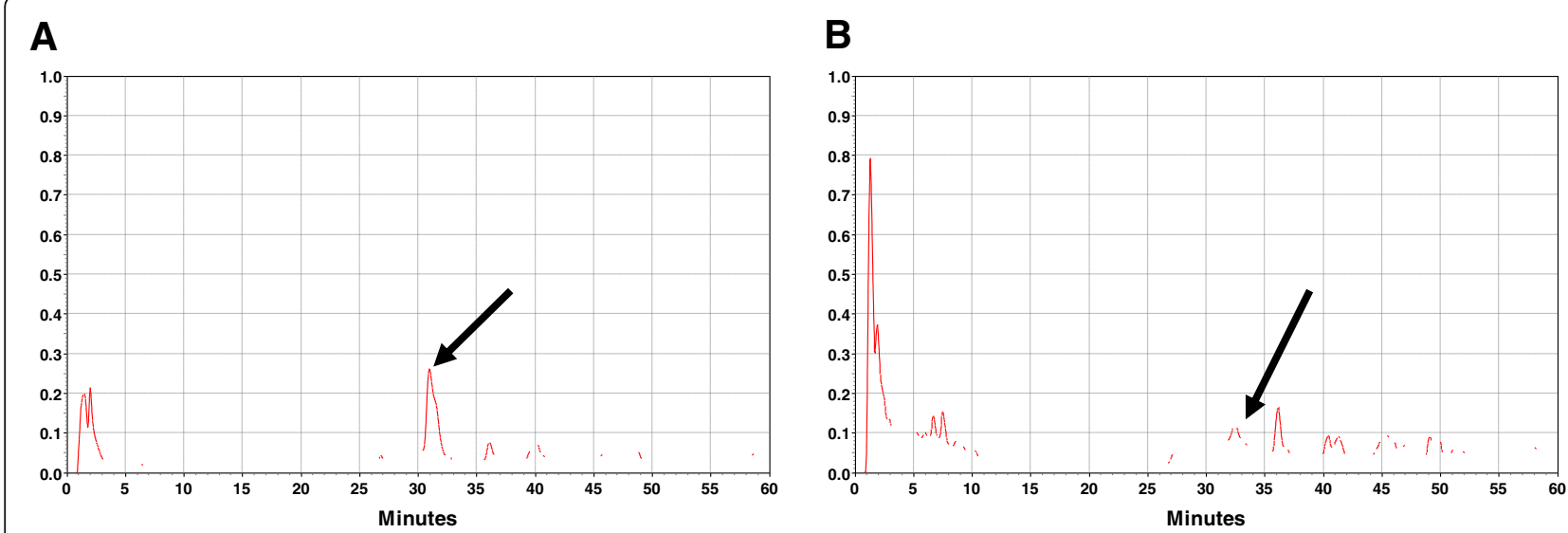

Fig. 1 a, HPLC chromtogram of a-solanine. b, HPLC chromatogram of SNME fraction. Arrow indicates the peak of a-solanine 

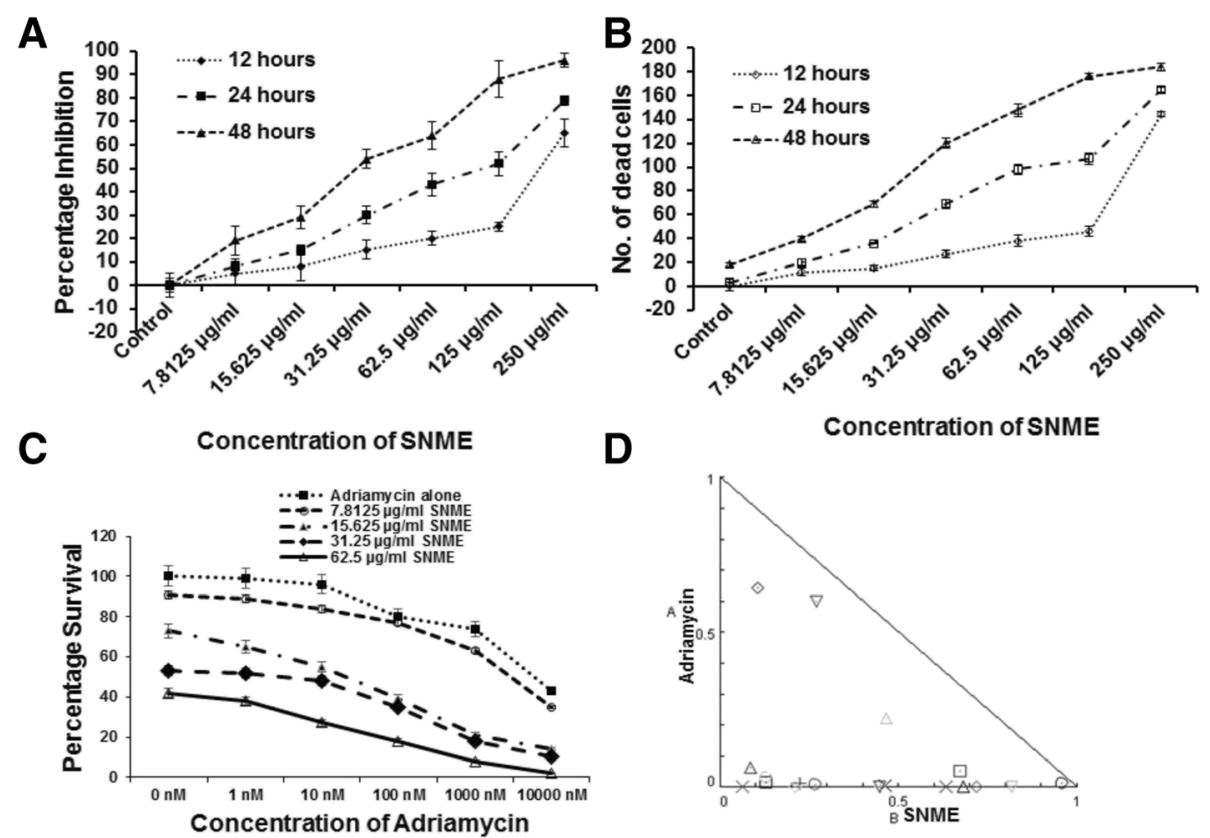

Fig. 2 a, Effects of SNME on NCI/ADR-RES cell proliferation. Cells were treated with 7.8125, 15.625, 31.25, 62.5, 125 and 250 $\mu \mathrm{g} / \mathrm{ml}$ of methanolic extract for 12, 24 and $48 \mathrm{~h}$. Control cells were maintained in the vehicle for the indicated time periods. The percentage inhibition increases as the concentration of SNME increases and the $\mathrm{IC}_{50}$ value obtained was $125 \mu \mathrm{g} / \mathrm{ml}$ at $24 \mathrm{~h}$. Results are represented as mean \pm SEM of three assays. $\mathbf{b}$, Effects of SNME on NCI/ADR-RES cell viability. Cells were treated with 7.8125, 15.625, 31.25, 62.5, 125 and $250 \mu \mathrm{g} / \mathrm{ml}$ of methanolic extract for 12 , 24 and $48 \mathrm{~h}$. Control cells were maintained in the vehicle for the indicated time periods. Results are represented as mean \pm SEM of three assays. c, Effects of Adriamycin and Adriamycin-SNME combination treatment on NCI/ADR-RES cell proliferation. Cells were treated with increasing concentration of Adriamycin ( $1 \mathrm{nM}-10,000 \mathrm{nM}$ ) with SNME ranging from 7.8125-62.5 $\mu \mathrm{g} / \mathrm{ml}$ of methanolic extract for $48 \mathrm{~h}$. Control cells were maintained in the vehicle for the indicated time periods. There was a synergistic action making the NCI/ADR RES cell lines sensitive to Adriamycin treatment in combination with SNME. Results are represented as mean \pm SEM of three assays. $\mathbf{d}$, Isobologram analysis of NCI/ADR RES cell lines in combination treatment with Adriamycin and SNME. Data calculated from surviving fractions following $48 \mathrm{~h}$ drug incubation. The diagonal line represents the isoeffect line of additivity. Each point is the mean determined from experiments performed in triplicate. Combination index (Cl) values calculated using Compusyn software is represented by points above (indicate antagonism between drugs) or below the lines (indicate synergy)

action which sensitizes the cells and enhances the efficacy of the Adriamycin to kill the cancerous drug resistant cells.

\section{SNME promotes sub G1 phase accumulation}

To determine whether the SNME mediated inhibition of cell proliferation was the result of cell cycle arrest induced apoptosis; we analyzed the DNA content of cells by propidium iodide staining followed by flow cytometry analysis. The NCI/ADR-RES cells were treated with $125 \mu \mathrm{g} / \mathrm{ml}$ of SNME for different time intervals ranging from $6 \mathrm{~h}$ to $24 \mathrm{~h}$ resulting in the accumulation of cells at sub G1 phase clearly indicating the onset of cell death (Fig. 3).

\section{SNME triggers apoptosis}

Morphological changes associated with apoptosis were evaluated by using phase contrast microscopy. Hoescht staining and ethidium bromide-acridine orange dual staining (Fig. 4a) was used to visualize nuclear condensation and onset of apoptosis. Vehicle treated cells were intact and homogeneously stained. Cells treated with SNME showed nuclear condensation. The number of cells with condensed nucleus increased with dose and time as evident in Fig. 4b.

Further to confirm SNME induce apoptosis, we performed Annexin V FITC staining. There was a notable increase $(24.5 \%)$ in the number of apoptotic population after treatment with SNME $-125 \mu \mathrm{g} / \mathrm{ml}$ for $24 \mathrm{~h}$ (Fig. 4c). The DNA fragmentation assay also showed laddering of DNA at various concentrations (Fig. 4d) of SNME giving evidence to its apoptotic potential. Cleavage of PARP was also observed on dose and time dependent treatment of SNME on NCI/ADR-RES cells (Fig. 5a).

\section{SNME down regulates the expression of Mdr-1}

To elucidate the relationship between STAT3 and multi drug resistance, we observed the expression pattern of Mdr-1, the multidrug resistance protein that help in drug efflux mechanism, after treatment with SNME. As shown in Fig. 5a, the expression of Mdr-1 was found to 

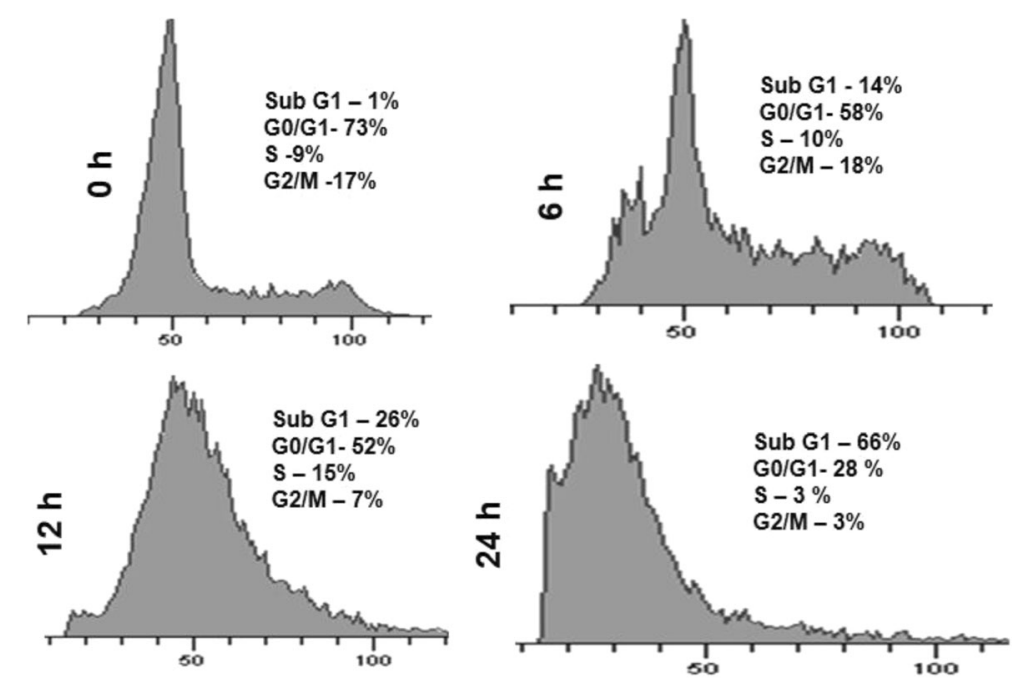

Fig. 3 Effects of SNME on cell division cycle of asynchronously growing NCI/ADR-RES cells. Cells were treated with $125 \mu \mathrm{g} / \mathrm{ml}$ of methanolic extract for 0, 6, 12 and $24 \mathrm{~h}$, stained with propidium iodide and analyzed by flow cytometry for DNA content. An increase in Sub $G_{0}$ phase indicated DNA fragmentation, a prerequisite for apoptosis

be decreased in a dose dependent manner after treatment with SNME. This probably indicates that cytotoxicity of NCI/ADR-RES cells was elevated owing to STAT3 inhibition.

\section{SNME treatment down regulates STAT3 expression}

The activity of STAT3 is usually higher in MDR tumors, and inhibition of STAT3 activity might reverse chemoresistance (Duan et al. [26]). In this study, we looked for the effect of SNME on STAT3 expression. It was observed that treatment with SNME decreased the expression of STAT3 in a dose dependent manner, along with JAK1. The expression of phosphorylated STAT3 (Tyr705) was also found to be decreased in a concomitant manner (Fig. 5). Interestingly there was not much variation in the expression level of phosphorylated STAT3 (ser727) after treatment with SNME (Fig. 5). These results suggest that deactivation of STAT3 could increase drug accumulation by suppressing Mdr1 expression.

\section{Discussion}

The effectiveness of chemotherapy is seriously limited by multi-drug resistance which is mediated mainly by P-gp and Mdr-1. Since the early 1980s, some compounds were found to overcome P-gp-mediated MDR. However, they had only limited success in clinical trials. Therefore, the characterization of signaling pathways sustaining MDR is thus essential for designing rational novel therapies [31]. This notion is supported by the data in the present study showing that inhibition of STAT3 pathway down regulated Mdr-1 expression in adriamycin resistant NCI/ADR-RES cells.
The main goal of this study was to investigate the effect of SNME of unripe $S$. nigrum fruits on cell growth and apoptosis induction in adriamycin resistant cell line NCI/ADR-RES. S. nigrum being a minor food crop of Solanaceae family, our preliminary results attributing its antineoplastic function warrants a deeper molecular understanding on the implication of solanum glycosides as a whole in chemo-sensitization. Initially, we observed that treatment with $S$. nigrum dramatically induced active inhibition of DNA synthesis. This result is in agreement with a previous study showing that $S$. nigrum exhibited anti-neoplastic effect on several human tumor cell lines [32]. In addition, since number of cells stained with MTT or trypan blue excluded were decreased with increased time and dose of the treatment (Fig. 2a and b), we hypothesized that SNME mediated inhibition of DNA synthesis may be exerted through a cytotoxic effect, rather than a cytostatic effect. Subsequently, we analyzed whether the cytotoxic effect is mediated via an apoptotic pathway. As evidenced by the presence of increased number of positively stained cells in Annexin $\mathrm{V}$ assay (Fig. 4c), PARP cleavage (Fig. 5) and the characteristic fragmentation of nuclear DNA (Fig. 4d) after SNME treatment, it appeared that apoptosis was the main mechanism for the cytotoxic effect of SNME on NCI/ ADR-RES cells. Since it has been suggested that apoptosis plays a critical role in tissue homeostasis and cancer development, the modulation of apoptosis has become an interesting target for both therapeutic and preventive approaches to cancer treatment [33].

Accumulating evidence supported that activated STAT3 might be a target for anti-tumor treatment. In this study, we observed that expression of STAT3 and JAK1 was 


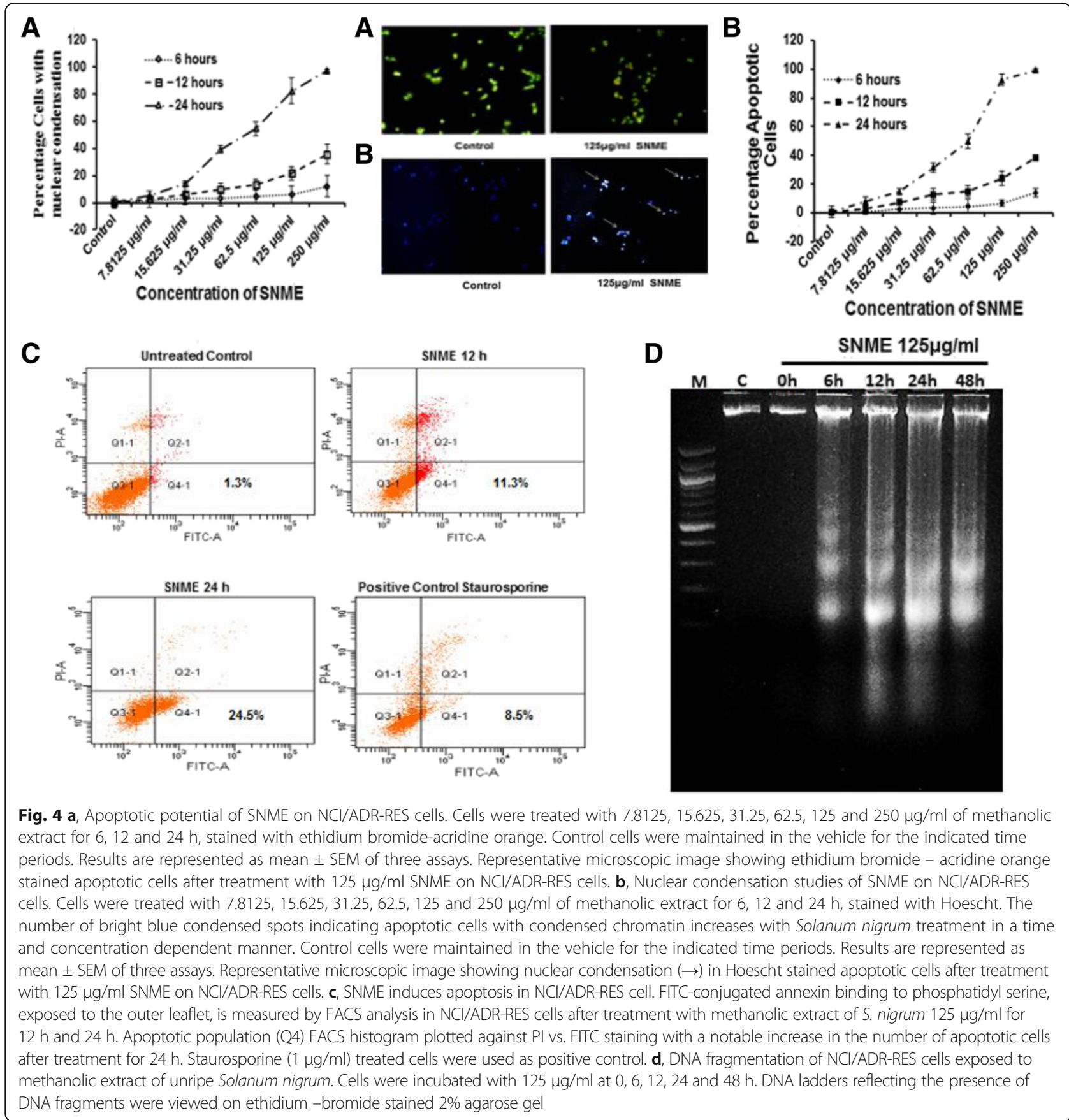

down regulated in SNME treated cells in a time and concentration dependent manner (Fig. 5a). JAK-STAT signaling is an important transduction pathway between cell survival and apoptosis. JAK1-dependent STAT3 activation has been reported to promote tumor cell cycling, survival, and invasiveness, enhance telomerase activity and modulate angiogenesis $[19,21,34,35]$. It is generally accepted that the tyrosine phosphorylation of STATs is a prerequisite for their DNA binding and transactivation, although growth factors and cytokines induce phosphorylation of
STATs on both tyrosine and serine. Earlier studies have shown that serine phosphorylation is required for the DNA binding of Stat3 in certain cell types. However, it was demonstrated later that phosphorylation on Ser-727 is not necessary for its DNA binding, but is required for the full transcriptional activity of Stat1 and Stat3. On the other hand, a negative effect of Ser-727 phosphorylation on the tyrosine phosphorylation of Stat3 has also been suggested [36]. In addition it is reported that phosphoS727 has an intrinsic mechanism for shortening the 


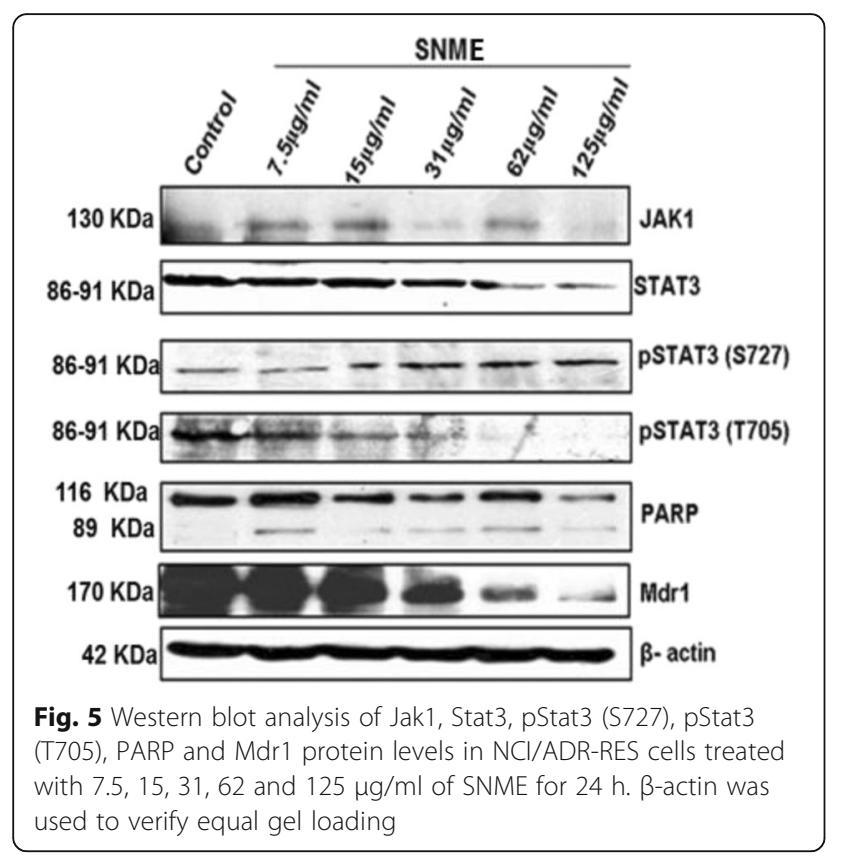

duration of STAT3 activity specifically by enhancing dephosphorylation of phospho-Tyr705 [37, 38]. The STAT3 signaling cascade is frequently activated in cancer cells and results in enhanced resistance of these cells to apoptosis through multiple mechanisms [39]. Given the substantial biological and molecular evidence supporting STAT3 as a valid target and the increasing number of human tumors that harbor constitutively-active STAT3, novel anticancer therapeutic modalities based on STAT3 inhibition will have widespread therapeutic applications. Thus Solanum nigrum can either be used as standalone agent or in combination with chemotherapy or other molecular-targeted therapeutic agents. Down regulation of these genes by Solanum nigrum also could contribute to this compound's potent cell cycle arrest and apoptotic effect on cancer cells.

Furthermore, Zhang et al. [31], reported that dephosphorylation of STAT3 reverses chemotherapeutics resistance of leukemia cells via down-regulating P-gp. In our study, we observed that treatment of NCI/ADR-RES cells with SNME down regulated the expression of Mdr1 (Fig. 5a) which may also contribute to its cytotoxic effect. Several studies aimed to modulate MDR1 gene and P-gp expression to improve the effects of some drugs, increasing the efficacy of treatments of certain diseases [40]. Modulation of P-gp can affect drug bioavailability, increase or decrease penetration of its substrates into the central nervous system, and affect the therapeutic efficacy [17, 41, 42]. Bourguignon et al. [27], reported that Nanog complexes with STAT3 can transactivate Mdr1 gene. However, in our study we observed inhibition of STAT3 expression, which leads to delayed STAT3 mediated transactivation of Mdr1 gene contributing to its down regulation. In summary, the present study elucidated a novel role of unripe $S$. nigrum fruit extract in inhibiting cellular proliferation and promoting apoptosis in Adriamycin resistant cell line NCI/ADR-RES, which further suggested that STAT3 could be a potential target in modulating drug resistant cancers.

\section{Conclusion}

The effectiveness of chemotherapy is seriously limited by multi-drug resistance, mediated mainly by P-glycoprotein (P-gp) and multi-drug resistance protein 1 (Mdr-1). In our study, we analyzed the effect of methanolic extract of unripe fruits of $S$. nigrum in combating multi-drug resistance (Mdr-1) expression and inducing apoptosis in Adriamycin resistant cells (NCI/ADR-RES) via the JAK-STAT pathway. The higher activity of STAT3 is usually associated within multi-drug resistant (MDR) tumors, and inhibition of STAT3 activity might reverse chemo-resistance. Our findings suggest that methanolic extract of unripe fruits of $S$. nigrum could be used as a chemo-sensitizing agent for Adriamycin resistant cancer cells and there by surpass chemo-resistance via inhibiting the JAK-STAT3 pathway.

\section{Abbreviations \\ ABCB1: ATP Binding Cassette Subfamily B Member 1; ADR-RES: Adriamycin Resistance; FITC: Fluorescein isothiocyanate; HPLC: High Performance Liquid Chromatography; JAK1: Janus Kinase 1; Mdr: Multi drug resistance; $\mathrm{NCl}$ : National Cancer Institute; OD: Optical Density; PARP: Poly ADP Ribose Polymerase; P-gp: P glycoprotein; SNME: Solanum nigrum Methanolic Extract; STAT: Signal Transducer and Activator of Transcription}

\section{Acknowledgements}

We thank Mrs. Indu Ramachandran for the flow cytometry analysis. We also thank Department of Biotechnology, Ministry of Science and Technology, India for the financial support for this study.

\section{Funding}

We thank Department of Biotechnology, Ministry of Science and Technology, India for the intramural financial support for this study.

Availability of data and materials

Not relevant to the study. Will be able to provide if requested.

\section{Authors' contributions}

SJ and DD, designed and performed all the cell based assays. JS and MS isolated, semi purified the plant extract. SJ, DD, JS and ASN wrote the manuscript. ASN and MS coordinated the work. SJ, DD and JS equally contributed to the work and share equal authorship. All authors read and approved the final manuscript.

\section{Ethics approval and consent to participate}

The study does not involve any human or animal subjects.

\section{Consent for publication}

All authors hereby provide the consent for publication.

Competing interests

The authors declare that they have no competing interests.

\section{Publisher's Note}

Springer Nature remains neutral with regard to jurisdictional claims in published maps and institutional affiliations. 


\section{Author details}

Cancer Research Program, Rajiv Gandhi Centre for Biotechnology, Thiruvananthapuram, Kerala, India. ${ }^{2}$ Plant Molecular Biology, Rajiv Gandhi Centre for Biotechnology, Thiruvananthapuram, Kerala, India. ${ }^{3}$ Department of Genetics, Dr. ALM Post Graduate Institute of Basic Medical Sciences, University of Madras, Taramani Campus, Chennai, Tamil Nadu, India.

\section{Received: 24 December 2016 Accepted: 5 July 2017}

\section{Published online: 18 July 2017}

\section{References}

1. Ferlay J, Soerjomataram I, Ervik M, Dikshit R, Eser S, Mathers C, Rebelo M, Parkin DM, Forman D, Bray F. GLOBOCAN 2012. Cancer incidence and mortality worldwide: IARC Cancer Base no. 11. International Agency for Research on Cancer: Lyon, France; 2013.

2. Ashraf RA, Sarfraz A, Mahmood A, Din MU. Chemical composition and in vitro antioxidant and antitumor activities of Eucalyptus camaldulensis Dehn. Leaves. Ind Crop Prod. 2015;74:241-8.

3. Paschka AG, Butler R, Young CYF. Induction of apoptosis in prostate cancer cell lines by the green tea component, $\beta$-epigallocatechin-3-gallate. Cancer Lett. 1998;130:1-7.

4. Nabekura T, Kamiyama S, Kitagawa S. Effects of dietary chemopreventive phytochemicals on P-glycoprotein function. Biochem Biophys Res Commun. 2005:327:866-70.

5. Kumar VP, Shashidhara S, Kumar MM, Sridhara BY. Cytoprotective role of Solanum nigrum against gentamicin-induced kidney cell (Vero cells) damage in vitro. Fitoterapia. 2001;72:481-6.

6. Heo KS, Lee SJ, Ko JH, Lim K, Lim KT. Glycoprotein isolated from Solanum nigrum inhibits the DNA-binding activities of NF-KB and AP-1, and increases the production of nitric oxide in TPA stimulated MCF-7 cells. Toxicol in Vitro. 2004;18:755-63.

7. An L, Tang J, Liu XM, Gao NN. Review about mechanisms of anti-cancer of Solanum nigrum. Zhongguo Zhong Yao Za Zhi. 2006;31:1225-6.

8. Zhou X, He X, Wang G, Gao H, Zhou G, Ye W, Yao X. Steroidal saponins from Solanum nigrum. J Nat Prod. 2006;69:1158-63.

9. Ji YB, Gao SY, Ji CF, Zou X. Induction of apoptosis in HepG2 cells by solanine and BCl-2 protein. J Ethnopharmacol. 2008;115:194-202.

10. Son YO, Kim J, Lim JC, Chung Y, Chung GH, Lee JC. Ripe fruits of Solanum nigrum L. inhibit cell growth and induce apoptosis in MCF-7 cells. Food Chemical Toxicology. 2003;41:1421-8

11. Lee JS, Lim KK, Lim KT. 150 kDa glycoprotein isolated from Solanum nigrum Linne enhances activities of detoxicant enzymes and lowers plasmic cholesterol in mouse. Pharmacol Res. 2005;51:399-408

12. Lim KT. Glycoprotein isolated from Solanum nigrum L kills HT-29 cells through apoptosis. J Med Food. 2005;8:215-26.

13. Li J, Li QW, Feng T, Zhang T, Li K, Zhao R, Han Z, Gao D. Antitumor activity of crude polysaccharides isolated from Solanum nigrum Linne on U14 cervical carcinoma bearing mice. Phytother Res. 2007;21:832-40.

14. Lin HM, Tseng HC, Wang CJ, Chyau CC, Liao KK, Peng PL, Chou FP. Induction of autophagy and apoptosis by the extract of Solanum nigrum Linn in HepG2 cells. J Agric Food Chem. 2007;55:3620-8.

15. Ravi V, Saleem TSM, Patel SS, Ramamurthy J, Gauthaman K. Anti-inflammaton effect of Methanolic extract of Solanum nigrum Linn berries. Int J Appl Res Nat Prod. 2009;2:33-6

16. Xie $R$, Hammarlund-Udenaes $M$, de Boer AG, de Lange EC. The role of $P$ glycoprotein in blood-brain barrier transport of morphine: transcortical microdialysis studies in MDR1a (-/-) and MDR1b (+/+) mice. Br J Pharmacol. 1999:128:563-8.

17. Wang JS, Ruan Y, Taylor RM, Donovan JL, Markowitz JS, DeVane CL. Brain penetration of methadone (R)- and(S)- enantiomers is greatly increased by $\mathrm{P}$ - glycoprotein deficiency in the blood-brain barrier of Abcb1a gene knockout mice. Psychopharmacology. 2004;173:132-8.

18. leiri I, Takane H, Otsubo K. The MDR1 (ABCB1) gene polymorphism and its clinical implications. Clin Pharmacokinet. 2004;43:553-76.

19. Buettner R, Mora LB, Jove R. Activated STAT signaling in human tumors provides novel molecular targets for therapeutic intervention. Clin Cancer Res. 2002:8:945-54

20. Turkson J, Jove R. STAT proteins: novel molecular targets for cancer drug discovery. Oncogene. 2000;19:6613-26.

21. Yu H, Jove R. The STATS of cancer-new molecular targets come of age. Nat Rev Cancer. 2004:4:97-105.
22. Lau CK, Yang ZF, Lam SP, Lam CT, Ngai P, Tam KH, Poon RT, Fan ST. Inhibition of Stat3 activity by YC-1 enhances chemo-sensitivity in hepatocellular carcinoma. Cancer Biol Ther. 2007;6:1900-7.

23. Sredni B, Weil M, Khomenok G, Lebenthal I, Teitz S, Mardor Y, Ram Z, Orenstein A, Kershenovich A, Michowiz S, Cohen Yl, Rappaport ZH, Freidkin I, Albeck M, Longo DL, Kalechman Y. Ammonium trichloro (dioxoethylene-0,0') tellurate (AS101) sensitizes tumors to chemotherapy by inhibiting the tumor interleukin 10 autocrine loop. Cancer Res. 2004;64:1843-52.

24. Zhou J, Ong CN, Hur GM, Shen HM. Inhibition of the JAK-STAT3 pathway by andrographolide enhances chemosensitivity of cancer cells to doxorubicin. Biochem Pharmacol. 2010:79:1242-50.

25. Ikuta K, Takemura K, Kihara M, Nishimura M, Ueda N, Naito S, Lee E, Shimizu E, Yamauchi A. Overexpression of constitutive signal transducer and activator of transcription 3 mRNA in cisplatin-resistant human non-small cell lung cancer cells. Oncol Rep. 2005:13:217-22.

26. Duan Z, Foster R, Bell DA, Mahoney J, Wolak K, Vaidya A, Hample C, Lee H, Seiden MV. Signal transducers and activators of transcription 3 pathway activation in drug-resistant ovarian cancer. Clin Cancer Res. 2006;12:5055-63.

27. Bourguignon LY, Peyrollier K, Xia W, Gilad E. Hyaluronan-CD44 interaction activates stem cell marker Nanog, Stat-3-mediated MDR1 gene expression, and ankyrin-regulated multidrug efflux in breast and ovarian tumor cells. J Biol Chem. 2008:283:17635-51.

28. Jisha S, Sreeja S, Manjula S. In vitro and in vivo estrogenic activity of glycoside fractions of Solanum nigrum fruits. Indian J Med Res. 2011:134:369-74.

29. Chou TC. Drug combination studies and their synergy quantification using the Chou-Talalay method. Cancer Res. 2010:70:440-6.

30. Chou TC, Martin N. CompuSyn for drug combinations: PC software and User's guide: a computer program for Quantitation of synergism and antagonism in drug combinations, and the determination of IC50 and ED50 and LD50 values. Paramus, (NJ): ComboSyn Inc; 2005.

31. Zhang $X$, Xiao W, Wang L, Tian Z, Zhang J. Deactivation of signal transducer and activator of transcription 3 reverses chemotherapeutics resistance of leukemia cells via down-regulating P-gp. PLoS One. 2011;6:e20965.

32. Hu K, Kobayashi H, Dong A, Jing Y, Iwasaki S, Yao X. Antineoplastic agents IIl: steroidal glycosides from Solanum nigrum. Planta Med. 1999:65:35-8.

33. Ahmad N, Feyes DK, Nieminen AL, Agarwal R, Mukhtar H. Green tea constituent epigallocatechin-3-gallate and induction of apoptosis and cell cycle arrest in human carcinoma cells. J Nat Cancer Institute. 1997;89:1881-6.

34. Bowman T, Garcia R, Turkson J, Jove R. STATs in oncogenesis. Oncogene. 2000;19:2474-88.

35. Turkson J. STAT proteins as novel targets for cancer drug discovery. Expert Opin Ther Targets. 2004:8:409-22.

36. Lim PC, Cao X. Serine phosphorylation and negative regulation of Stat3 by JNK. J Biol Chem. 1999:274(43):31055-61.

37. Chung J, Uchida E, Grammer CT, Blenis J. STAT3 serine phosphorylation by ERK-dependent and independent pathways negatively modulates its tyrosine phosphorylation. Mol Cell Biol. 1997;17:6508-16.

38. Wakahara R, Kunimoto $H$, Tanino K, Kojima H, Inoue A, Shintaku H, Nakajima K Phospho-Ser727 of STAT3 regulates STAT3 activity by enhancing dephosphorylation of phospho-Tyr705 largely through TC45. Genes Cells. 2012;17:132-45.

39. Siddiquee AL, Zaid K, Turkson J. STAT3 as a target for inducing apoptosis in solid and hematological tumors. Cell Res. 2008;18:254-7.

40. Mickisch GH, Pastan I, Gottesman MM. Multidrug resistant transgenic mice as a novel pharmacologic tool. BioEssays. 1991:13:381-7.

41. Mizuno N, Niwa T, Yotsumoto $Y$, Sugiyama $Y$. Impact of drug transporter studies on drug discovery and development. Pharmacol Rev. 2003:55:425-61.

42. Dagenais C, Graff CL, Pollack GM. Variable modulation of opioid brain uptake by P-glycoprotein in mice. Biochem Pharmacol. 2004;67:269-76. 